\title{
Biomarkers of Traumatic Injury Are Transported from Brain to Blood via the Glymphatic System
}

\author{
Benjamin A. Plog, ${ }^{1,2 \star}$ Matthew L. Dashnaw, ${ }^{1 \star}$ Emi Hitomi, ${ }^{1}$ Weiguo Peng, ${ }^{1}$ Yonghong Liao, ${ }^{1}$ Nanhong Lou, ${ }^{1}$ \\ Rashid Deane, ${ }^{1}$ and ${ }^{\circledR}$ Maiken Nedergaard ${ }^{1}$ \\ ${ }^{1}$ Center for Translational Neuromedicine, Department of Neurosurgery and ${ }^{2}$ Department of Pathology, University of Rochester Medical Center, Rochester, \\ New York 14642
}

The nonspecific and variable presentation of traumatic brain injury (TBI) has motivated an intense search for blood-based biomarkers that can objectively predict the severity of injury. However, it is not known how cytosolic proteins released from traumatized brain tissue reach the peripheral blood. Here we show in a murine TBI model that CSF movement through the recently characterized glymphatic pathway transports biomarkers to blood via the cervical lymphatics. Clinically relevant manipulation of glymphatic activity, including sleep deprivation and cisternotomy, suppressed or eliminated TBI-induced increases in serum S100 $\beta$, GFAP, and neuron specific enolase. We conclude that routine TBI patient management may limit the clinical utility of blood-based biomarkers because their brain-toblood transport depends on glymphatic activity.

Key words: biomarker; CSF; clearance; lymphatic; traumatic brain injury

\section{Introduction}

Traumatic brain injury (TBI) has emerged as a growing public health challenge. According to the Centers for Disease Control and Prevention, an estimated 1.7 million people will suffer a TBI each year in the United States alone (Faul et al., 2010; Roozenbeek et al., 2013), and $\sim 5.3$ million people must manage disability attributable to a TBI (Langlois and Sattin, 2005; Roozenbeek et al., 2013). In recent years, there has been an increase in the number of military personnel exposed to traumatic head injury, leading the Department of Defense to designate TBI as the signature injury of the troops serving in Iraq and Afghanistan (Hoge et al., 2009). The nonspecific nature of TBI symptomatology (Darwish et al., 2012; Mannix et al., 2013), compounded by the variable presentation of TBI, has made the diagnostic and prognostic approach challenging. Not surprisingly, considerable effort has been directed toward identifying a panel of peripheral blood markers reflective of the severity of brain injury. Among the biomarkers receiving the greatest clinical attention are the cytosolic proteins $\mathrm{S} 100 \beta$, GFAP, and neuron specific enolase (NSE), which leak out of glial cells or neurons with plasma membrane damage. It is currently not completely understood how these biomarkers reach the peripheral blood. Conventional thinking is that disrup-

\footnotetext{
Received Sept. 8, 2014; revised Nov. 2, 2014; accepted Nov. 7, 2014.

Author contributions: B.A.P. and M.N. designed research;B.A.P., M.L.D., E.H., W.P., Y.L., N.L., and R.D. performed research; B.A.P., M.L.D., E.H., and R.D. analyzed data; B.A.P., M.L.D., and M.N. wrote the paper.

This work was supported by the National Institutes of Health (to M.N.), the United States Department of Defense (to M.N.), and the Harold and Leila Y. Mathers Charitable Foundation (to M.N.).

The authors declare no competing financial interests.

*B.A.P. and M.L.D. contributed equally to this work.

Correspondence should be addressed to Dr. Maiken Nedergaard, University of Rochester Medical Center School of Medicine and Dentistry, 601 Elmwood Avenue, Box 645, Rochester, NY 14642. E-mail: Maiken_Nedergaard@URMC.Rochester.edu.

DOI:10.1523/JNEUROSCI.3742-14.2015

Copyright $\odot 2015$ the authors $\quad 0270-6474 / 15 / 350518-09 \$ 15.00 / 0$
}

tion of the blood-brain barrier (BBB) results in diffusion of biomarkers from the site of injury into the general circulation (Chodobski et al., 2011; Mondello et al., 2011; Obermeier et al., 2013); however, the exact role of the BBB or alternate routes of biomarker efflux from the CNS has not been established using a systematic approach.

Recent work shows that CSF, driven in part by arterial pulsatility, enters the brain via the periarterial space and interchanges with interstitial fluid (ISF) (Iliff et al., 2012, 2013a, b). This highly organized system of CSF-ISF exchange has been called the glymphatic system because it shares many similarities with the lymphatic system in peripheral tissue, and the presence of glial aquaporin-4 (AQP4) water channels facilitates its activity (Iliff et al., 2012). ISF and its constituent solute are recollected along perivenous spaces, from where this fluid can either recirculate via the subarachnoid CSF or, alternatively, drain from the intracranial cavity along myelin sheaths of cranial and spinal nerves to perineural lymphatics and, to a lesser extent, through arachnoid granulations (Johnston and Papaiconomou, 2002). In rodents as well as in humans, a large proportion of CSF drainage occurs within the myelin sheath of the olfactory bulbs via the cribiform plate, ultimately being delivered to the deep cervical lymphatics after CSF exits within the nasal mucosa (Bradbury et al., 1980; Bradbury and Westrop, 1983; Cserr et al., 1992; Boulton et al., 1996; Johnston et al., 2004; Iliff et al., 2012; Murtha et al., 2014). Thus, the traditionally described olfactory-cervical lymphatic clearance route and the more recently identified perivascular glymphatic pathway do not represent discrete efflux mechanisms but, rather, exist in series within the same system. The importance of protein transport by the glymphatic system is best illustrated by the finding that it accounts for as much as $65 \%$ of the clearance of exogenously delivered amyloid- $\beta$ (Iliff et al., 2012). 
Here, we evaluate the contribution of the glymphatic system in transport of TBI biomarkers to the peripheral blood.

\section{Materials and Methods}

Animals. Female C57BL/6 mice, 8-12 weeks of age (Charles River Laboratories) were used for all experiments, unless otherwise specified. Aquaporin-4 knock-out (AQP4KO, Aqp $4^{-1-}$ ) mice were generated as described previously (Thrane et al., 2011). Mice expressing the fusion protein of vascular endothelial growth factor receptor 3 and yellow fluorescent protein (VEGR3-YFP) were generated as previously detailed (Calvo et al., 2011). All experiments were approved by the University Committee on Animal Resources of the University of Rochester and performed according to guidelines from the National Institutes of Health (protocol number 2011-023).

Awake "hit and run" TBI model. TBI was induced with a commercially available controlled cortical impact device, specifically the Pneumatic Powered Controlled Cortical Impact Device (Pittsburgh Precision Instruments). Several modifications to the traditional use of the device were implemented. Nonanesthetized mice were first placed head first into a small, plastic, cone-shaped bag (726409, Harvard Apparatus). Slits were cut at the narrow end of the bag to allow for increased comfort and ventilation space. An opening corresponding to the location of impact on the mouse was also cut into the bag to prevent glancing of the impactor tip. Once in the restraint bag, a twist-tie was placed behind each mouse to immobilize it. Using a previously fashioned $0.5 \mathrm{~cm}$ loop of 4-0 nylon suture (Ethicon), attached to the bag, the bagged mouse was suspended vertically, with the head up, by a mounted metal ring as previously described (Ren et al., 2013) (see Fig. 2a).

The controlled cortical impact mounting apparatus was rotated $90^{\circ}$, such that the metal rod was positioned horizontally, and a $3 \mathrm{~mm}$ polished stainless steel tip, which strikes the mouse's head during the impact, was fitted to the end of the impactor slide. In this study, we used an impactor velocity of $4.7 \mathrm{~m} / \mathrm{s}$, an impact depth of $10 \mathrm{~mm}$, and impact duration of $100 \mathrm{~ms}$. The location of the impact was the point $4.5 \mathrm{~mm}$ lateral to midline and $4.5 \mathrm{~mm}$ posterior to the left orbit. A firm, wooden barrier was placed $5 \mathrm{~cm}$ anterior to the suspended mouse, which the animal struck following impact to provide a consistent component of deceleration injury. Following impact, mice were removed from the bag and recovered while being observed for health and pain in a private cage where food and water were available. All injured mice received a single impact. Control animals underwent the bag and tie procedure, as well as the vertical hang, but were not struck.

Inhibition of glymphatic-associated CSF-ISF exchange. As detailed below, we used four unique methods to inhibit glymphatic bulk flow:

Aqp $4^{-/-}$mice. Aquaporin-4 knock-out (AQP4KO, Aqp $4^{-1-}$ ) mice were generated as described previously (Thrane et al., 2011). AQP4KO mice were killed $18 \mathrm{~h}$ following TBI or intracortical cannula placement.

Cisterna magna cisternotomy. Mice randomized to the cisternotomy group were anesthetized with a mixture of ketamine $(100 \mathrm{mg} / \mathrm{kg}$, i.p.) and xylazine $(10 \mathrm{mg} / \mathrm{kg}$, i.p.) promptly after TBI or intracortical cannula placement (see below). The mice were then placed in the prone position with the head slightly flexed. A $5 \mathrm{~mm}$ linear incision was made over the occipital-cervical junction with skull and neck musculature reflected inferolaterally down to the cisterna magna. With the aid of a Zeiss operating microscope, a horizontal cisternotomy was fashioned with a beveled 30-gauge needle (BD Biosciences) so that CSF could flow freely. While the edges of the skin were reapproximated with 5-0 nylon suture (Ethicon), the cisternotomy was left open to continually drain CSF for a total of $18 \mathrm{~h}$, until the time of animal death. Animals recovered while being observed for health and pain in a private cage where food and water were available.

Acetazolamide treatment. For mice randomized to the acetazolamide treatment group, $20 \mathrm{mg} / \mathrm{kg}$ of drug was delivered via the intraperitoneal route every $6 \mathrm{~h}$ commencing after TBI or intracortical cannula placement (see below) and continuing for the subsequent $18 \mathrm{~h}$ (total of 4 injections), until the time of animal death.

Sleep deprivation. For mice randomized to the sleep deprivation group, gentle sleep deprivation began after TBI or intracortical cannula placement (see below) and continued for the following $18 \mathrm{~h}$ (6:00 P.M. to
12:00 P.M. the following day). Sleep deprivation was undertaken using a modified mouse cage with a motorized rotating bar (7 revolutions per minute) slightly above the floor which lightly nudges the animal encouraging low levels of activity. Food and water remained available throughout the sleep deprivation period.

Blood serum collection and ELISA. Mice were anesthetized with a mixture of ketamine (100 mg/kg, i.p.) and xylazine (10 mg/kg, i.p.), and blood samples were obtained by cardiac puncture $18 \mathrm{~h}$ after TBI. The blood samples underwent centrifugation of 10,000 rpm for $10 \mathrm{~min}$ in 2 $\mathrm{ml}$ Protein LoBind tubes (Eppendorf), after which the serum supernatant was transferred to $0.5 \mathrm{ml}$ Protein LoBind tubes (Eppendorf) and stored at $-80^{\circ} \mathrm{C}$ until analysis. Commercially available ELISA kits were used in the analysis of serum samples for S100 $\beta$ (EZHS100B-33K, Human S100B ELISA, EMD Millipore), GFAP (NS830, GFAP ELISA, EMD Millipore), and NSE (MBS702407, Mouse NSE ELISA, MyBioSource).

Intracortical cannula placement. For the deep cervical lymph node fluorescent protein imaging experiments, a stainless steel guide cannula (Plastics One) was stereotactically implanted into the left frontal cortex of anesthetized ( $2 \%$ isoflurane), uninjured mice. The coordinates of the cannula tip being at $1 \mathrm{~mm}$ posterior and $3.5 \mathrm{~mm}$ lateral to the bregma, and $1.5 \mathrm{~mm}$ below the surface of the brain. Animals were allowed to recover after surgery, and the experiments performed $12-24 \mathrm{~h}$ after guide tube cannulation.

Intracortical fluorescent protein injection. To evaluate the extent of clearance of brain interstitial solute to the deep cervical lymphatics, the fluorescent tracer AlexFluor-555-ovalbumin (OA555, $45 \mathrm{kDa}$ ) (Invitrogen) was injected into the cerebral cortex guided by the stereotactically placed cannula detailed above. The tracer was constituted in artificial CSF to a final concentration of $1 \%$. Tracer injection commenced $18 \mathrm{~h}$ after glymphatic-reducing interventions began (12-24 h after cannula placement for AQP4 null and control mice). Mice were anesthetized with a mixture of ketamine (100 mg/kg, i.p.) and xylazine ( $10 \mathrm{mg} / \mathrm{kg}$, i.p.). For the injection, a 33-gauge needle (Plastics One) of equal length to the cannula was inserted into the cannula, and $0.5 \mu \mathrm{l}$ of tracer was injected at a rate of $0.1 \mu \mathrm{l} / \mathrm{min}$ over $5 \mathrm{~min}$. After the injection, the needle was left in place for an additional 25 min to prevent retrograde efflux of tracer. The needle was then withdrawn and the cannula plug reinserted. The animals were perfusion fixed $2 \mathrm{~h}$ following injection (see below).

In vivo epifluorescence lymph node imaging. Before commencement of intracortical fluorescent protein injection (as described above), mice were anesthetized with a combination of ketamine $(100 \mathrm{mg} / \mathrm{kg}$, i.p. $)$ and xylazine $(10 \mathrm{mg} / \mathrm{kg}$, i.p.). The skin overlying the anterior cervical region was shaved to remove all fur and then underwent incision and lateral reflection. To allow for visualization of deep cervical lymph structures, superficial cervical tissues underwent further lateral retraction using 5-0 nylon suture (Ethicon). A low-power $(1 \times)$ bright-field image of the dissection was taken before fluorescent protein injection on an Olympus SZX12 dissecting microscope (Olympus) using CellSens standard imaging software (version 1.2, Olympus). The entry of tracer into deep cervical lymph nodes was imaged in vivo by epifluorescence microscopy (MZ16FA, Leica). After placing the mouse supine on the microscope stage, low-power $(1 \times, 7.11 \times$ digital zoom $)$ micrographs were acquired in the red emission channel (captures OA555 fluorescence). Images were collected at $15 \mathrm{~min}$ intervals for $0-120 \mathrm{~min}$ following injection commencement using HCImage imaging software (version 1.1.2.0, Hamamatsu). Exposure and gain were held constant throughout the duration of the imaging sequence.

Deep cervical lymph node collection for fluorescent protein imaging: tissue collection and processing. For evaluating the clearance of fluorescent tracer from the site of injection in the cerebral cortex to the deep cervical lymph nodes, animals underwent transcardial perfusion with ice-cold 0.1 м PBS (PBS, pH 7.4, Sigma-Aldrich) followed by 4\% PFA (SigmaAldrich). The head and neck underwent overnight postfixation in $4 \%$ PFA. After postfixation, 1-2 deep cervical lymph nodes were microscopically harvested and mounted with Prolong Anti-Fade Gold 2 with DAPI (Invitrogen).

Ex vivo fluorescence imaging. The entry of tracer into deep cervical lymph nodes was evaluated ex vivo by epifluorescence microscopy (BX51, Olympus). Multichannel whole-node montages were acquired 
with the virtual slice module of Microlucida software (version 2.3.1, MicroBrightField). DAPI and red emission channels were acquired at low magnification $(4 \times)$. Exposure and gain were determined based upon control nodes and maintained constant for all study groups. Deep cervical lymph nodes from VEGFR3-YFP mice were evaluated ex vivo by confocal microscopy (IX81, Olympus). Low-magnification $(4 \times)$ images were acquired in the green and red emission channels using Fluoview software (version 4.3, Olympus).

Analysis of fluorescent images. To quantify tracer entry into deep cervical lymph nodes, the lymph node images were analyzed using ImageJ software (National Institutes of Health, imagej.nih.gov/ij/). For each node, fluorescence emission channels were split and a whole node ROI was defined based upon the DAPI signal. The red channel, corresponding to OA555, was background subtracted based upon an ROI outside of the lymph node area. The mean nodal fluorescence intensity was calculated and averaged for each animal (1-2 nodes per animal, 4-6 animals per group).

Radioisotope clearance. To evaluate solute clearance from the brain, radiolabeled tracers ${ }^{3} \mathrm{H}$-dextran $(40 \mathrm{kDa}$, American Radiolabeled Chemicals) and ${ }^{14} \mathrm{C}$-inulin (6 kDa, PerkinElmer) were injected stereotactically into the left frontal cortex, as we recently reported (Xie et al., 2013). Briefly, a stainless steel guide cannula (Plastics One) was implanted stereotactically into the left frontal cortex of anesthetized mice ( $2 \%$ isoflurane) with the coordinates of the cannula tip at $1.0 \mathrm{~mm}$ anterior and 3.5 $\mathrm{mm}$ lateral to the bregma, and $1.5 \mathrm{~mm}$ below the surface of the brain. Animals were allowed to recover after surgery, and the experiments performed 12-24 h after the guide tube cannulation, as reported (Cirrito et al., 2005; Deane et al., 2008; Xie et al., 2013). There were 5 groups of mice (4-6 per group): controls, cisterna magna cisternotomy, acetazolamide treatment (i.p., $20 \mathrm{mg} / \mathrm{kg}$ every $6 \mathrm{~h}$ for $18 \mathrm{~h}$ ), sleep deprivation, and AQP4KO mice. In each mouse, a small volume of mock CSF $(0.5 \mu \mathrm{l})$, containing ${ }^{3} \mathrm{H}$-dextran $(5 \mu \mathrm{Ci})$ and ${ }^{14} \mathrm{C}$-inulin $(0.05 \mu \mathrm{Ci})$, was injected ( 33 GA cannula, Plastics One) into the brain ISF over $5 \mathrm{~min}$. At the end of the experiments $(60 \mathrm{~min})$, the brain was removed and prepared for radioactivity analysis. The brain was solubilized in $0.5 \mathrm{ml}$ tissue solubilizer (PerkinElmer) overnight followed by the addition of $5 \mathrm{ml}$ of scintillation mixture (Ultima Gold, PerkinElmer). The injectate was treated in the same way. All samples were analyzed in a liquid scintillation counter (LS6500 Multipurpose Scintillation Counter, Beckman Coulter).

Calculations. The percentage of radioactivity remaining in the brain after microinjection was determined as percentage recovery in brain $=$ $100 \times\left(\mathrm{N}_{\mathrm{b}} / \mathrm{N}_{\mathrm{i}}\right)$, where $\mathrm{N}_{\mathrm{b}}$ is the radioactivity remaining in the brain at the end of the experiment and $\mathrm{N}_{\mathrm{i}}$ is the radioactivity injected into the brain ISF (i.e., the dpm of ${ }^{3} \mathrm{H}$-dextran and ${ }^{14} \mathrm{C}$-inulin). Clearance percentage was deduced from the percentage recovery as $100-(\%$ recovery). Dextran 40 and inulin were used, as they are metabolically inert, polar molecules that are neither transported across the BBB nor retained by the brain (Cserr and Ostrach, 1974; Amtorp, 1979; Binder et al., 2004; Thorne and Nicholson, 2006; Iliff et al., 2012; Xie et al., 2013); their clearance provides a measure of the ISF bulk flow.

Assessment of $B B B$ permeability. For quantification of BBB leakage, a $2 \%$ solution of Evans Blue (ICN Biomedical) in normal saline (4 ml/ $\mathrm{kg}$ of body weight) was injected by the intraperitoneal route (Manaenko et al., 2011). The dye was allowed to circulate for $18 \mathrm{~h}$ following the traumatic head injury, at which point the brains were havested.

Tissue collection and processing. Mice were transcardially perfused with ice-cold 0.1 м PBS (pH 7.4, Sigma-Aldrich) followed by 4\% PFA (SigmaAldrich). Cerebral tissue was carefully dissected from the calvarium and postfixed overnight in 4\% PFA. Following fixation, cerebral tissue was sliced on a calibrated vibratome (VT1000P, Leica Microsystems) into 100 $\mu \mathrm{m}$ sections. Beginning at $1.11 \mathrm{~mm}$ from the bregma, every third tissue section was collected until a total of 12 sections had been acquired for tissue imaging. Brain sections were mounted with Prolong Antifade Gold 2 with DAPI (Invitrogen).

Ex vivo fluorescence imaging. The brain uptake of Evans Blue was evaluated ex vivo by epifluorescence microscopy (BX51, Olympus). Multichannel whole-slice montages were acquired with the virtual slice module of Microlucida software (version 2.31, MicroBrightField). DAPI and red emission channels were acquired at low magnification $(4 \times)$.
Exposure and gain were determined based upon control brain slices and maintained constant for all study groups.

Analysis of Evans Blue images. To quantify Evans Blue entry into brain tissue, and hence the extent of blood brain barrier permeability, the whole-slice montage images were analyzed using ImageJ software (National Institutes of Health, imagej.nih.gov/ij/). For each slice, fluorescence emission channels were split and a whole-brain ROI was defined based upon the DAPI signal. The red channel, corresponding to Evans Blue emission, was background subtracted based upon an ROI outside of the brain slice area. The area of positive fluorescence (thresholded pixel intensity $>100$ A.U.) was calculated and then summed across all 12 slices within a brain. The total pixel area of the ROI outlining each slice was also measured and summed across all 12 slices. For each brain, the summed positive fluorescent area was represented as a ratio of the summed total pixel area. This ratio was then averaged across all brains in a group (4 or 5 animals per group).

Statistical analysis. Statistical analysis was performed with the aid of GraphPad Prism 6.0c (GraphPad Software). The resulting values from radioisotope clearance, lymph node fluorescence, ELISA serum sample analyses, and brain slice Evans Blue fluorescence were evaluated using a one-way ANOVA with the Tukey post hoc test for multiple comparisons. Left versus right control lymph node fluorescence was evaluated using a paired $t$ test. Probability values $<0.05$ were deemed significant. All values are expressed as the mean \pm SEM.

\section{Results}

To determine the contribution of the glymphatic system in the transport of biomarkers of TBI to the peripheral blood, we used four unique approaches to suppress glymphatic-associated clearance. These manipulations were chosen because their mechanisms of action are fundamentally different from one another, and none affect the integrity of the BBB. The manipulations included the following: (1) AQP4 deletion, (2) cisterna magna cisternotomy, (3) acetazolamide treatment, and (4) sleep deprivation. (1) Mice lacking the AQP4 water channel have previously been shown to exhibit slowed glymphatic CSF influx kinetics and consequently a decrease in interstitial solute clearance (Iliff et al., 2012). (2) Cisterna magna cisternotomy leads to the physical drainage of CSF and thereby a reduction or blockage of glymphatic fluxes, whereas (3) systemic administration of acetazolamide reduces CSF production at the choroid plexus through the inhibition of $\mathrm{HCO}_{3}^{-}$formation (Vogh et al., 1987). The latter two manipulations lead to a loss of the hydraulic driving force within the subarachnoid and interstitial spaces, and ultimately suppression of CSF-ISF exchange, which is responsible for convective glymphatic clearance of solutes from the brain. Additionally, in the wake state, the extracellular volume fraction is small, generating higher tissue resistance toward ISF fluxes (Xie et al., 2013). (4) Sleep deprivation therefore leads to failure of convective flow through the interstitial space resulting in reduced glymphatic efflux.

\section{Glymphatic suppression inhibits clearance of intracortical tracers to the deep cervical lymphatics}

To directly visualize the effect of the four manipulations on glymphatic-cervical lymphatic exchange (Bradbury et al., 1980; Bradbury and Westrop, 1983; Cserr et al., 1992; Boulton et al., 1996; Johnston et al., 2004; Murtha et al., 2014), we injected a fluorescently tagged fixable protein tracer, AlexaFluor-555ovalbumin (OA555, $45 \mathrm{kDa}$ ) into the cerebral cortex and quantified lymph node accumulation $2 \mathrm{~h}$ after injection. Time-lapse, in vivo imaging of the anterior cervical lymphatic architecture demonstrated that OA555 injected into cortex exits CNS via the cervical lymphatics and accumulates in the associated lymph nodes (Fig. 1a). Transgenic mice expressing a fusion protein 
a

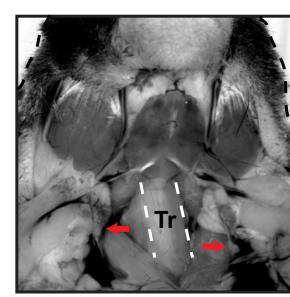

b

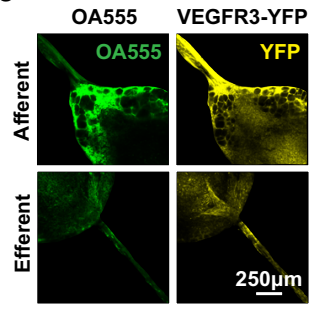

f

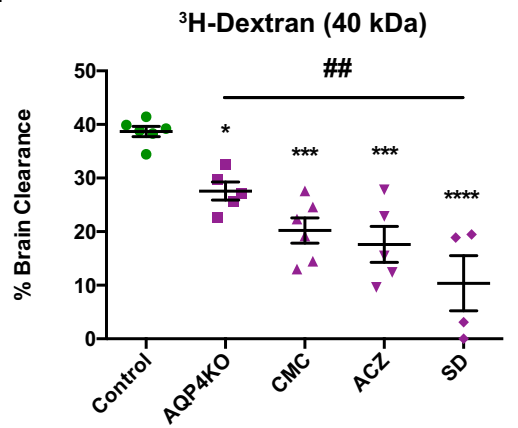

$t=0-\min$

C
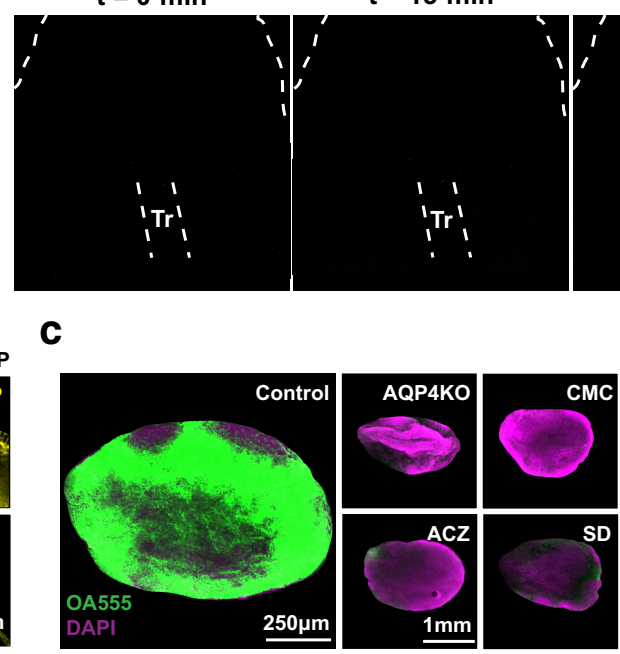

g
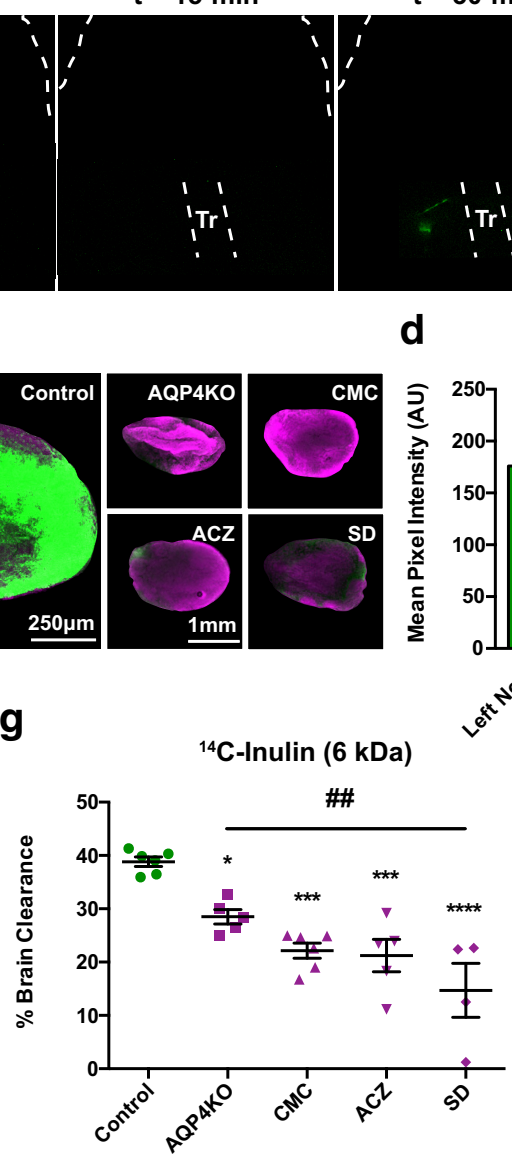

d $t=30-\min$
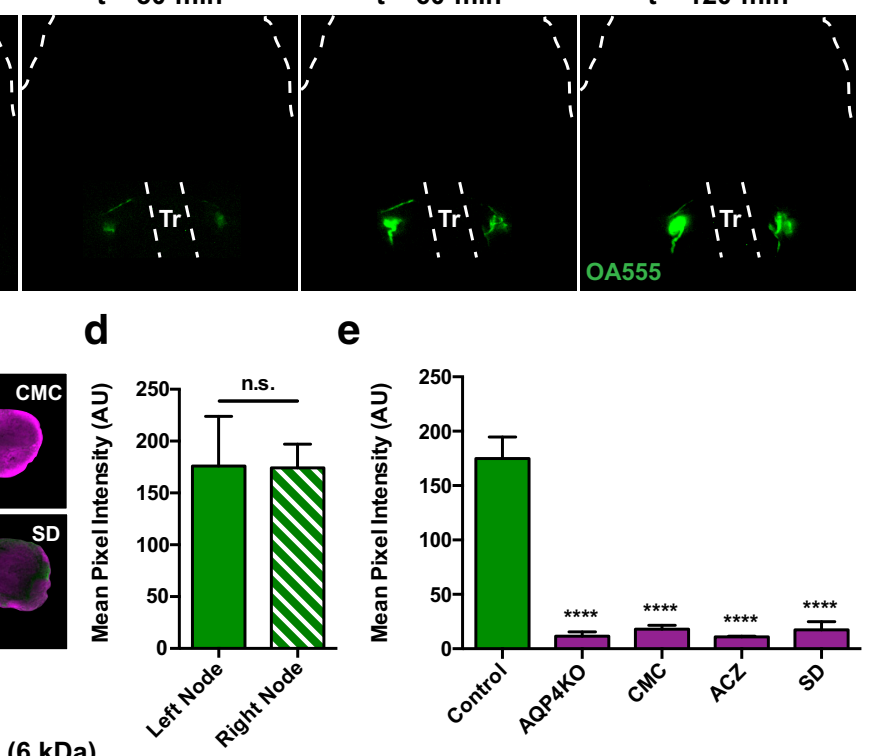

Figure 1. Glymphatic clearance of intracortical injected tracers can be suppressed with genetic, pharmacological, and mechanical manipulations. $\boldsymbol{a}$, Time-lapse, in vivo imaging demonstrates that, subsequent to intracortical delivery, 0A555 exits CNS via anterior cervical lymph vessels and accumulates in associated lymph nodes. Left, Bright-field image. Right, Epifluorescent micrographs acquired in the red emission channel $(1 \times, 7.11 \times$ digital zoom) between 0 and 120 min following intracortical 0 A555 injection. Arrows indicate location of deep cervical lymph nodes. Tr, Trachea. $\boldsymbol{b}$, Low-power confocal micrographs ( $4 \times$ ) acquired $2 \mathrm{~h}$ following intracortical OA555 injection in VEGFR3-YFP mice confirm tight colocalization of $0 A 555$ signal with the highly specific lymphatic endothelial cell marker. Top, Deep cervical node with afferent lymph vessel demonstrating high VEGFR3 expression. Bottom, Efferent vessel exiting node. $c-e$, Epifluorescent imaging (4X) of OA555 clearance to the deep cervical lymph nodes $2 \mathrm{~h}$ following intracortical delivery (c) revealed no significant lateralization of fluorescence in control lymph nodes (d). When left and right nodes were pooled within individual animals, there were significantly lower node mean pixel intensities with aquaporin-4 knock-out (AQP4KO), cisterna magna cisternotomy (CMC), acetazolamide (ACZ, $20 \mathrm{mg} / \mathrm{kg}$, i.p.) treatment, and sleep deprivation (SD) compared with control conditions (e). $\boldsymbol{f}, \boldsymbol{g}$, Liquid scintillation counting of whole-brain homogenates revealed significantly reduced 60 min clearance of ${ }^{3} \mathrm{H}$-dextran $(\boldsymbol{f})$ and ${ }^{14} \mathrm{C}$-inulin $(\boldsymbol{g})$ due to aquaporin-4 knock-out, cisterna magna cisternotomy, acetazolamide treatment, or sleep deprivation. All graphs represent mean \pm SEM. ${ }^{*} p<$ 0.05 versus control (one-way ANOVA, Tukey post hoc analysis). ${ }^{* * *} p<0.001$ versus control (one-way ANOVA, Tukey post hoc analysis). ${ }^{* * *} p<0.0001$ versus control (one-way ANOVA, Tukey post hoc analysis). \#\#p $<0.01$ versus AQP4KO (one-way ANOVA, Tukey post hoc analysis). n.s., Not significant (paired $t$ test). $n=4-6$ mice per group.

of the lymphatic endothelial cell marker vascular endothelial growth factor receptor 3 and yellow fluorescent protein (VEGFR3-YFP) (Kaipainen et al., 1995; Calvo et al., 2011) confirmed that intracortical OA555 was draining specifically to cervical lymphatic structures (Fig. 1b). To evaluate the efficacy by which manipulation of the glymphatic system affected OA555 efflux, we quantified fluorescent signal intensity within the deep cervical nodes of $A Q P 4 K O$, cisterna magna cisternotomized, acetazolamide treated, and sleep-deprived mice as well as controls (Fig. 1c,d). The analysis showed that the interventions all reduced accumulation of the glymphatic tracer OA555 in cervical lymph nodes. We next quantified the efficiency by which these manipulations reduced glymphatic clearance by conventional radiolabeled intracortical injections. The tracers, ${ }^{3} \mathrm{H}$-dextran $(40 \mathrm{kDa})$ and ${ }^{14} \mathrm{C}$-inulin $(6 \mathrm{kDa})$, were chosen because they are not transported across the BBB and are similar in molecular weight to commonly evaluated injury biomarkers (Cserr and Ostrach, 1974; Amtorp, 1979; Binder et al., 2004; Thorne and Nicholson, 2006; Iliff et al., 2012; Xie et al., 2013). This analysis showed that mice with deletion of AQP4, cisterna magna cisternotomy, acetazolamide treatment, or sleep deprivation exhibited a sharp reduction in clearance of each of these radio-labeled tracer molecules versus control mice (Fig. 1e,f). Thus, all four manipulations potently blocked convective glymphatic solute clearance, albeit their mechanistic bases are distinct.

\section{Suppression of glymphatic pathway activity prevents the} delivery of TBI biomarkers to the serum

We next sought to determine how suppression of the glymphatic pathway would impact blood entry of endogenous brain solutes, specifically molecules released in response to TBI. A controlled cortical impact model (Xiong et al., 2013), "hit and run" (Ren et al., 2013), was modified for nonanesthetized mice to mitigate the confounding neuroprotection provided by anesthesia (Statler et al., 2006) (Fig. 2a). A dorsolateral, closed-head TBI was delivered in wild-type and AQP4KO mice. Briefly, awake mice were suspended vertically within a plastic restraint cone, allowing a horizontally oriented controlled cortical impact device to strike the 
a

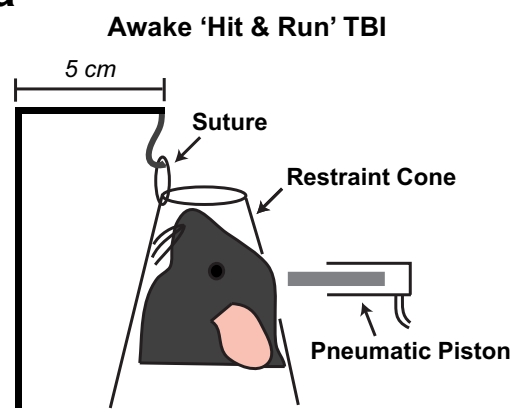

C

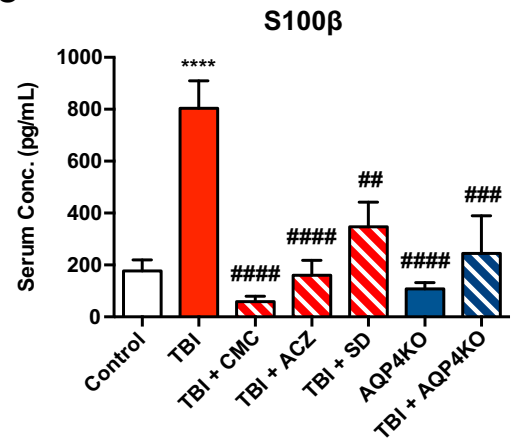

b

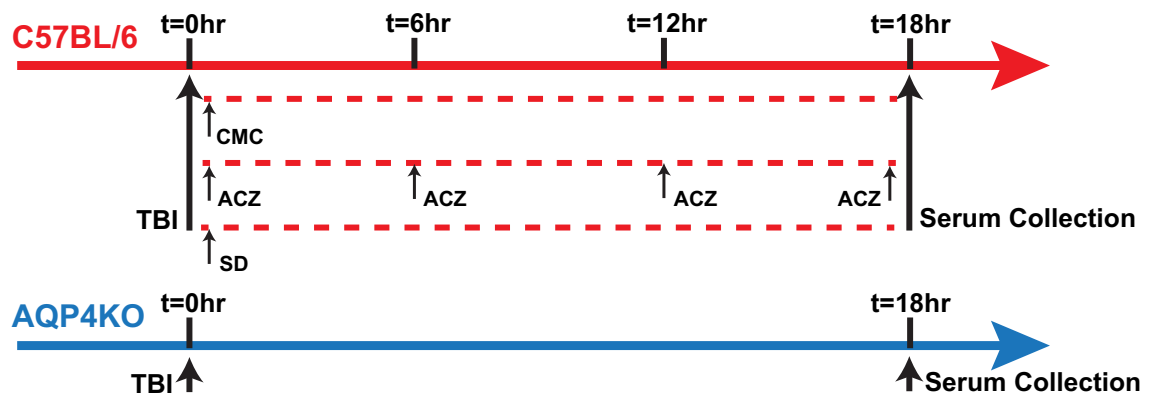

d

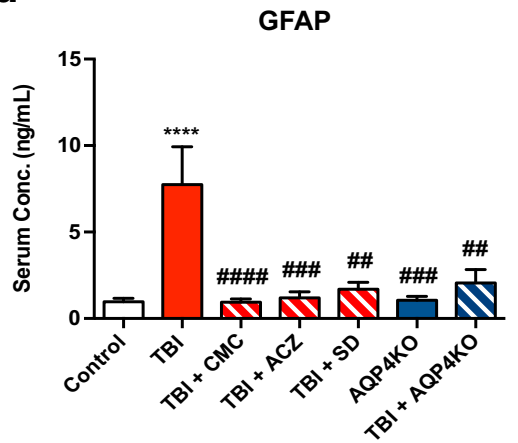

e

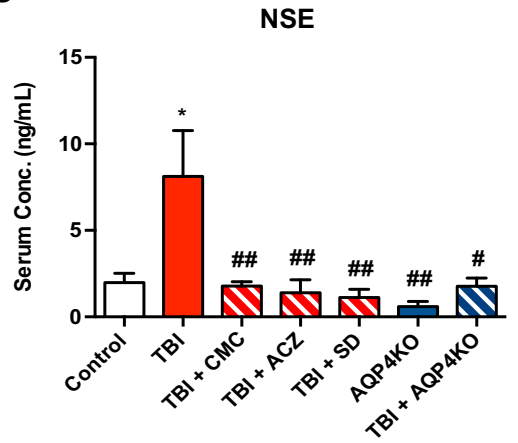

Figure 2. Suppression of glymphatic clearance prohibits the delivery of TBI biomarkers to the serum. $\boldsymbol{a}$, Schematic representation of nonanesthetized, closed-head "hit and run" TBI model. $\boldsymbol{b}$, Experimental timeline: "hit and run" TBI is induced in C57BL/6 and aquaporin-4 knock-out (AQP4KO) mice. Subgroups of C57BL/6 mice then receive cisterna magna cisternotomy (CMC), acetazolamide (ACZ, $20 \mathrm{mg} / \mathrm{kg}$, i.p.) treatment, or sleep deprivation (SD) immediately following TBI. Serum is collected $18 \mathrm{~h}$ subsequent to TBI and submitted for ELISA analysis of S100 $\beta$, GFAP, and NSE levels. $\boldsymbol{c}-\boldsymbol{e}$, ELISA analysis of serum levels of S100 $\beta(\boldsymbol{c})$, GFAP (d), and NSE $(\boldsymbol{e})$ reveals no demonstrable differences at baseline between C57BL/6 and aquaporin-4 knock-out mice. There is a significant elevation in all three of these biomarkers of brain injury $18 \mathrm{~h}$ following TBI. When TBI was given in conjunction with aquaporin-4 knock-out, cisterna magna cisternotomy, acetazolamide treatment, or sleep deprivation, the concentrations of all three markers in blood were significantly reduced relative to TBI alone and were not significantly different from levels seen in injury naive mice. All graphs represent mean \pm SEM. ${ }^{*} p<0.05$ versus control (one-way ANOVA, Tukey posthoc analysis). ${ }^{* * *} p<0.0001$ versus control (one-way ANOVA, Tukey post hoc analysis). ${ }^{\#} p<0.05$ versus TBI (one-way ANOVA, Tukey post hoc analysis). ${ }^{\# \#} p<0.01$ versus TBI (one-way ANOVA, Tukey posthoc analysis). ${ }^{\# \#} p<0.001$ versus TBI (one-way ANOVA, Tukey post hoc analysis). ${ }^{\# \# \# p<}$ 0.0001 versus TBI (one-way ANOVA, Tukey post hoc analysis). $n=4-10$ mice per group.

dorsal calvarium (Fig. 2a). Following impact, the mouse was removed from the restraint cone and allowed to recover while freely ambulating in its home cage. This model integrates components of direct impact and acceleration-deceleration injury. Subgroups of wild-type mice were exposed to cisterna magna cisternotomy, acetazolamide treatment, or sleep deprivation. Importantly, these three interventions were first implemented following TBI. Serum was then collected from each mouse $18 \mathrm{~h}$ subsequent to TBI and submitted to ELISA for a panel of clinically relevant biomarkers of brain injury (Fig. $2 b$ ).

$\mathrm{S} 100 \beta$ is the most extensively studied marker of head injury in both adults and children (Papa et al., 2013). It is a member of a family of low-molecular weight calcium-binding proteins comprised of combinations of $\alpha$ - and $\beta$-chains (Kövesdi et al., 2010). $\mathrm{S} 100 \beta(10.5 \mathrm{kDa})$, a $\beta$-chain homodimer, is enriched in brain, specifically in the cytoplasm of astrocytes (Kövesdi et al., 2010; Jeter et al., 2013). Although elevated serum levels of $S 100 \beta$ have been thought of as indicative of astrocytic injury, the expression of $S 100 \beta$ in peripheral cells, such as Schwann cells, chondrocytes, and adipocytes (Kövesdi et al., 2010; Olsson et al., 2011; Zetterberg et al., 2013), has confounded evaluation of injury severity in the setting of polytrauma, and $S 100 \beta$ can be elevated in the serum of injured athletes without head trauma (Herrmann, 2001; Zetterberg et al., 2013). For this reason, GFAP has emerged as a promising marker specific for head injury. GFAP $(52 \mathrm{kDa})$ is the principal intermediate filament making up the astroglial cytoskeleton (Brenner et al., 2001; Kövesdi et al., 2010) and, contrary to $S 100 \beta$, has an expression specific to astrocytes, being released into the interstitial space in response to various injury states (Kövesdi et al., 2010; Diaz-Arrastia et al., 2014). NSE (78 kDa) is a glycolytic enzyme that exists as a heterodimer constructed from $\alpha, \beta$, and $\gamma$ subunits. The $\gamma-\gamma$ isoform is predominantly found in neurons, and being released into the extracellular space following injury, is the protein marker receiving the greatest attention as a direct indicator of neuronal injury and death (Kövesdi et al., 2010; Papa et al., 2013). Following severe TBI in adults, peak serum S100 $\beta$ levels are achieved between 6 and $24 \mathrm{~h}$ after brain trauma, and similarly, peak GFAP concentrations are seen in the peripheral blood within the first $24 \mathrm{~h}$ after TBI. In contrast, the post-traumatic peak of NSE occurs within $12 \mathrm{~h}$ and will begin to decrease during the subsequent hours (Kövesdi et al., 2010). Based on these studies, serum biomarker levels were here assayed at $18 \mathrm{~h}$ following TBI, a time point where overlapping serum concentration curves allow for simultaneous detection of the earlier peaking NSE and the later rising GFAP and $S 100 \beta$.

Assessment of serum S100 $\beta$, GFAP, and NSE before TBI in C57BL/6 and AQP4KO mice revealed no significant differences in the level of these markers (Fig. $2 c-e$ ). When serum biomarker levels were evaluated $18 \mathrm{~h}$ after experimental TBI induction, there was a significant elevation relative to baseline of $S 100 \beta$, GFAP, and NSE in wild-type mice, but not with $A Q P 4 K O$ (Fig. $2 c-e$ ). Similarly, when the glymphatic pathway was inhibited by cisterna magna cisternotomy, acetazolamide treatment, or sleep deprivation subsequent to TBI in wild-type mice, the serum level of all 
a

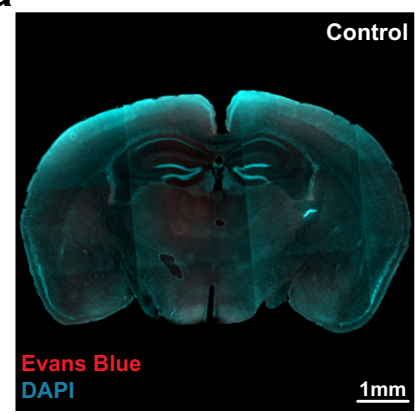

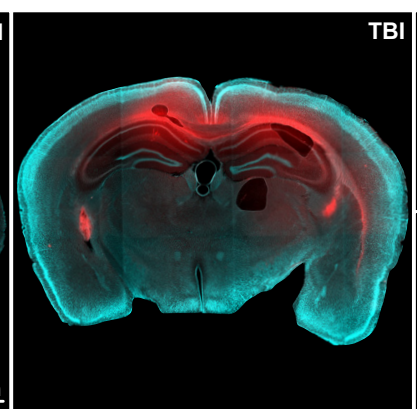

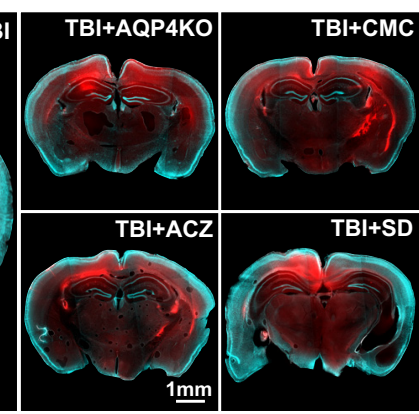

b

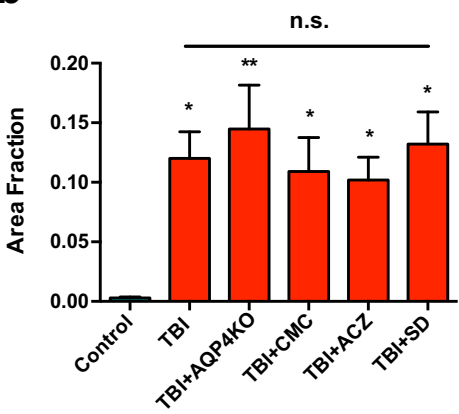

Figure 3. BBB permeability is not affected by manipulations of glymphatic clearance. $\boldsymbol{a}, \boldsymbol{b}$, Fluorescent imaging of brain Evans Blue ( $\boldsymbol{a}$ ) reveals that there are no demonstrable differences in BBB permeability among mice receiving TBI alone and those receiving a TBI superimposed with aquaporin-4 knock-out (AQP4KO), cisterna magna cisternotomy (CMC), acetazolamide (ACZ, 20 mg/kg, i.p.) treatment, or sleep deprivation (SD) (b). All graphs represent mean \pm SEM. n.s., Not significant. ${ }^{*} p<0.05$ versus control (one-way ANOVA, Tukey post hoc analysis). ${ }^{* *} p<0.01$ versus control (one-way ANOVA, Tukey post hoc analysis). $n=4$ or 5 mice per group.

three biomarkers of injury was significantly suppressed relative to mice receiving TBI alone and was not significantly different from wild-type mice that were trauma naive (Fig. $2 c-e$ ). Thus, regardless of approach, suppression of the glymphatic clearance pathway resulted in failure of the delivery of these endogenously produced injury markers to the peripheral blood at levels sufficient to accurately predict injury presence or severity.

Suppression of glymphatic pathway activity does not decrease post-traumatic $\mathrm{BBB}$ permeability

An alternative explanation for the reduced serum level of all three TBI biomarkers after glymphatic inhibition would be that $A Q P 4 K O$, cisterna magna cisternotomy, acetazolamide treatment, and sleep deprivation decrease the secondary injury response to TBI, thereby lessening the degree of BBB opening and the access markers of brain injury have to the peripheral blood. To control for this possibility, we delivered Evans Blue systemically to evaluate BBB dysfunction and found that there were no demonstrable differences in $\mathrm{BBB}$ permeability among mice receiving TBI alone and those receiving a TBI superimposed with any of the above interventions (Fig. $3 a, b$ ). From this, we conclude that protection against secondary injury processes is not likely contributing to the observed reduction in serum biomarker levels when CSF-ISF exchange is inhibited.

Recent work has shown that Aqp4 gene deletion does not exacerbate traumatic lesion volume $28 \mathrm{~d}$ after TBI (Iliff et al., 2014), suggesting that this water channel does not significantly modify gross brain injury. Additionally, there is an extensive literature demonstrating that knock-out of AQP4 water channels will protect against the formation of cytotoxic edema and exacerbate the development of vasogenic edema (Manley et al., 2000; Papadopoulos et al., 2004; Papadopoulos and Verkman, 2007). In considering the role of AQP4 in these two processes, it is important to discriminate between brain edema formation and $\mathrm{BBB}$ breakdown, as development of the former is not necessarily a consequence of the latter. When there is cytotoxic cell swelling, AQP4 knock-out will, through a mechanism requiring further elaboration, prevent the movement of water from the cerebrovasculature into the brain proper across an intact BBB (Simard and Nedergaard, 2004; Liang et al., 2007; Papadopoulos and Verkman, 2007; Simard et al., 2007, 2012b; Kurland et al., 2012). Further, the progression of vasogenic edema after trauma has been shown to be worsened by AQP4 knock-out because of the necessity of this water channel in the clearance of excess parenchymal interstitial fluid (Papadopoulos et al., 2004), rather than as a consequence of altering the degree of BBB opening. Thus, although there is exhaustive data characterizing the role of AQP4 in the development and resolution of cytotoxic and vasogenic edema, in neither of these scenarios is there any evidence that this role is attributable to a direct influence on the extent of BBB permeation. This is in agreement with the data presented here showing an equivalent BBB conductance of Evans Blue in both wild-type and AQP4 knock-out mice receiving TBI (Fig. 3a,b). Because AQP4 channels were deleted before TBI, three other glymphatic-suppressing interventions, all with independent mechanisms and an absence of data demonstrating modulation of gross brain injury, edema formation, or functional outcome, were also used and demonstrated an equal extent of BBB permeation as was seen in wild-type and AQP4 knock-out mice after TBI (Fig. $3 a, b)$.

\section{Discussion}

In previous work, glymphatic CSF-ISF exchange has been shown to drive the removal of exogenous molecules, including albumin, amyloid, dextrans, and paramagnetic contrast agents, from the interstitial space of the brain (Iliff et al., 2012, 2013a). The present study is the first to provide evidence of this pathway playing a critical role in the clearance of endogenously produced proteins, in this case biomarkers of head injury, from the CNS to the peripheral blood. When various manipulations that suppress CSF-ISF exchange were applied after TBI, the near-complete knockdown of the appearance of biomarkers in the serum reveals the essential nature of the glymphatic pathway in clearance of brain-derived proteins. This observation does not exclude that a fraction of proteins or other molecules released from the cytosol of injured cells following TBI arrive in the blood via diffusional processes across a leaky BBB (Simard et al., 2010; 2012a; Mondello et al., 2011; Kurland et al., 2012), but it is clear that glymphatic transport constitutes the primary highway for CNS solute efflux.

It is interesting to note that, although the four mechanisms of glymphatic suppression result in differing degrees of inhibited radiotracer clearance (Fig. $1 f, g$ ), these same manipulations seem to decrease serum biomarker levels to an equal extent (Fig. $2 c-e$ ). This may be a consequence of there being a lower limit to glymphatic suppression, beyond which the glymphatic system is no longer contributing to the efflux of intracerebral protein. To quantify the magnitude of inhibition, while avoiding confounding factors, the radiotracer clearance studies were performed in noninjured control mice (not having received a TBI). The analy- 
sis of serum biomarkers levels following glymphatic knockdown, however, was necessarily performed in mice exposed to TBI. Recently, our group has demonstrated that TBI alone will decrease glymphatic pathway activity (Iliff et al., 2014). As a result, TBI, representing the second hit to the glymphatic system, may eliminate any residual clearance capacity in these mice and ultimately lead to an equal magnitude of serum biomarker decline.

The possibility that glymphatic-suppressing manipulations lead to reduced serum biomarker levels through decreased cellular injury, rather than inhibited clearance, must be acknowledged; however, this conclusion does not appear to be well supported by the data presented. Reported neuroprotection derived from AQP4 deletion is likely a consequence of mitigated cytotoxic cerebral edema. It has been well characterized that, in models of brain injury where cytotoxic cell swelling is induced, including hyponatremia, focal and global cerebral ischemia, and bacterial meningitis, genetic deletion or mislocalization of AQP4 will reduce the degree of edema development and lead to an improved functional outcome (Manley et al., 2000; AmiryMoghaddam et al., 2004; Marmarou, 2004, 2007; Papadopoulos and Verkman, 2005, 2007; Simard et al., 2007; Haj-Yasein et al., 2011; Akdemir et al., 2014; Katada et al., 2014). Cerebral edema, a secondary injury process, if uncontrolled, can lead to further ischemia, infarction, and, in the most severe cases, herniation and death (Marmarou, 2004, 2007; Simard et al., 2007). Thus, any intervention reducing edema formation and progression will also likely reduce cellular injury. Although the effects of AQP4 on cerebral edema are well documented, work from our laboratory has shown that Aqp4 gene deletion does not exacerbate gross lesion volume (Iliff et al., 2014); and to our knowledge, there is no evidence demonstrating that any of the remaining glymphatic suppressing interventions (cisternotomy, acetazolamide pharmacotherapy, or sleep deprivation) directly influence edema or other pathology development. As a consequence, there is no data to support the hypothesis that these three manipulations will alter the secondary injury response and the extent of neuronal or glial injury. Because the finding of reduced serum biomarker levels was reaffirmed with all four distinct methodologies, each with independent mechanisms of action, it is more probable that this result is a common consequence of suppressed glymphatic clearance kinetics, rather than a yet to be identified effect on the secondary injury response.

To definitively prove this conclusion would require assay of extracellular or CSF biomarker levels, which would be expected to increase with inhibition of glymphatic clearance. Methodological barriers resulting from glymphatic suppression, however, preclude collecting CSF or ISF samples. The normal total CSF volume in an adult mouse is $\sim 30-40 \mu \mathrm{l}$ (Rangroo Thrane et al., 2013). Draining CSF with cisternotomy or decreasing CSF production with acetazolamide therapy will prevent the collection of sufficiently large enough volumes for ELISA-based analyses, which typically require 50-100 $\mu \mathrm{l}$ of neat sample. Additionally, performing microdialysis would not be practical, as these interventions, by decreasing the CSF and ISF volume, may artificially concentrate extracellular biomarker levels. Further, even slight variance in the proximity of the cannula tip from the core of the TBI lesion, which is itself variable in size and shape, would result in drastically different ISF biomarker readings. Moreover, whereas large-pore microdialysis probes have been developed specifically for the assay of extracellular proteins, large-pore diameters can also permit the outward conductance of perfusate, resulting in the development of interstitial edema (Takeda et al., 2011). Push-pull microdialysis methodologies, where an equal volume of perfusate is simultaneously being added and removed from the probe, have been used to minimize positive outward pressure differentials across the catheter membrane. These techniques, however, result in inconsistent recovery rates due to slow diffusion of large molecular weight proteins, and pressures can still fluctuate across the membrane in free-moving animals (Takeda et al., 2011; Yamada et al., 2011; Ulrich et al., 2013), thus raising concerns that edema will be induced in the post-traumatic brain.

These observations are potentially of immediate clinical relevance. Although many biomarkers have been identified and studied over the last two decades, none has proved sufficiently useful for routine clinical use due to suboptimal sensitivity, specificity, and reproducibility after TBI (Kövesdi et al., 2010; Mondello et al., 2011; Jeter et al., 2013; Papa et al., 2013; Zetterberg et al., 2013; Diaz-Arrastia et al., 2014). The finding that common TBI biomarkers exit brain via the cervical lymph vessels offers an explanation for the difficulties in identifying ideal brain injury diagnostic or prognostic tools. Inhibition of glymphatic clearance, which greatly suppressed the concentration of biomarkers in serum after TBI, was induced by a series of clinically relevant manipulations. For example, it is commonplace to institute either sleep deprivation by performing frequent neurological assessments, or, depending on the clinical situation, to use barbiturates or other agents with sedative properties to induce a sleep-like state in patients after a TBI (Stone et al., 2014). Additionally, ventriculostomy (analogous to cisternotomy in our work) is variably used after severe TBI, as are pharmacologic interventions, which alter CSF production (Bratton et al., 2007). The usage and timing of these methods in relation to peripheral blood collection are expected to significantly affect the serum concentration of the biomarker independently of the extent of brain injury. These observations highlight the importance of developing a clinical tool, radiographic or biochemical in nature, for the evaluation of glymphatic-associated clearance in patients. This could provide a normalization index for serum biomarker levels and thus improve the diagnostic, prognostic, and therapeutic information provided by serum biomarker measurement. Perhaps more importantly, the effects of glymphatic pathway alteration on the short- or long-term sequelae of TBI have yet to be defined and may greatly alter the way we approach this clinical entity.

The exclusive use of female mice represents a limitation of the present study. Although TBI, with a male-to-female incidence ratio of $\sim 1.5: 1$ (Tagliaferri et al., 2006; Faul et al., 2010), is a disease with a disproportionate burden on males, it is important to recognize that the absolute incidence of TBI among females is significant across all age groups. Females aged 0-4 experience TBI at an annual rate of 1,218 per 100,000; and in women 75 years and older, the incidence equalizes with males at 932 per 100,000 (Faul et al., 2010). Further, although still controversial, the literature indicates that female gender may represent a risk factor for worse outcome subsequent to TBI. This may be particularly true in postmenopausal women no longer benefiting from the neuroprotective effects of estrogen and progesterone (Farace and Alves, 2000). At present, it is unknown whether TBI will differentially affect glymphatic function in females versus males and what impact this will have on the rate of biomarker clearance to the peripheral blood. Although beyond the scope of this study, answering this question will be an important area of future inquiry. 


\section{References}

Akdemir G, Ratelade J, Asavapanumas N, Verkman AS (2014) Neuroprotective effect of aquaporin-4 deficiency in a mouse model of severe global cerebral ischemia produced by transient 4 -vessel occlusion. Neurosci Lett 574:70-75. CrossRef Medline

Amiry-Moghaddam M, Xue R, Haug FM, Neely JD, Bhardwaj A, Agre P, Adams ME, Froehner SC, Mori S, Ottersen OP (2004) Alphasyntrophin deletion removes the perivascular but not endothelial pool of aquaporin-4 at the blood-brain barrier and delays the development of brain edema in an experimental model of acute hyponatremia. FASEB J 18:542-544. CrossRef Medline

Amtorp O (1979) Distribution of inulin, sucrose and mannitol in rat brain cortex slices following in vivo or in vitro equilibration. J Physiol 294:81-90. Medline

Binder DK, Papadopoulos MC, Haggie PM, Verkman AS (2004) In vivo measurement of brain extracellular space diffusion by cortical surface photobleaching. J Neurosci 24:8049-8056. CrossRef Medline

Boulton M, Young A, Hay J, Armstrong D, Flessner M, Schwartz M, Johnston M (1996) Drainage of CSF through lymphatic pathways and arachnoid villi in sheep: measurement of ${ }^{125} \mathrm{I}$-albumin clearance. Neuropathol Appl Neurobiol 22:325-333. CrossRef Medline

Bradbury MW, Westrop RJ (1983) Factors influencing exit of substances from cerebrospinal fluid into deep cervical lymph of the rabbit. J Physiol 339:519-534. Medline

Bradbury M, Deane R, Segal M, Westrop R (1980) Recovery of [ $\left.{ }^{125} \mathrm{I}\right]$ albumin in deep cervical lymph of the sheep after intra-ventricular injection. J Physiol 305:52.

Bratton SL, Chestnut RM, Ghajar J, McConnell Hammond FF, Harris OA, Hartl R, Manley GT, Nemecek A, Newell DW, Rosenthal G, Schouten J, Shutter L, Timmons SD, Ullman JS, Videtta W, Wilberger JE, Wright DW (2007) Guidelines for the management of severe traumatic brain injury: VI. Indications for intracranial pressure monitoring. J Neurotrauma 24 [Suppl 1]:S37-S44.

Brenner M, Johnson AB, Boespflug-Tanguy O, Rodriguez D, Goldman JE, Messing A (2001) Mutations in GFAP, encoding glial fibrillary acidic protein, are associated with Alexander disease. Nat Genet 27:117-120. CrossRef Medline

Calvo CF, Fontaine RH, Soueid J, Tammela T, Makinen T, Alfaro-Cervello C, Bonnaud F, Miguez A, Benhaim L, Xu Y, Barallobre MJ, Moutkine I, Lyytikkä J, Tatlisumak T, Pytowski B, Zalc B, Richardson W, Kessaris N, Garcia-Verdugo JM, Alitalo K, et al. (2011) Vascular endothelial growth factor receptor 3 directly regulates murine neurogenesis. Genes Dev 25: 831-844. CrossRef Medline

Chodobski A, Zink BJ, Szmydynger-Chodobska J (2011) Blood-brain barrier pathophysiology in traumatic brain injury. Transl Stroke Res 2:492516. CrossRef Medline

Cirrito JR, Yamada KA, Finn MB, Sloviter RS, Bales KR, May PC, Schoepp DD, Paul SM, Mennerick S, Holtzman DM (2005) Synaptic activity regulates interstitial fluid amyloid-beta levels in vivo. Neuron 48:913-922. CrossRef Medline

Cserr HF, Ostrach LH (1974) Bulk flow of interstitial fluid after intracranial injection of blue dextran 2000. Exp Neurol 45:50-60. CrossRef Medline

Cserr HF, Harling-Berg CJ, Knopf PM (1992) Drainage of brain extracellular fluid into blood and deep cervical lymph and its immunological significance. Brain Pathol 2:269-276. CrossRef Medline

Darwish H, Mahmood A, Schallert T, Chopp M, Therrien B (2012) Mild traumatic brain injury (MTBI) leads to spatial learning deficits. Brain Injury 26:151-165. CrossRef Medline

Deane R, Sagare A, Hamm K, Parisi M, Lane S, Finn MB, Holtzman DM, Zlokovic BV (2008) apoE isoform-specific disruption of amyloid beta peptide clearance from mouse brain. J Clin Invest 118:4002-4013. CrossRef Medline

Diaz-Arrastia R, Wang KK, Papa L, Sorani MD, Yue JK, Puccio AM, McMahon PJ, Inoue T, Yuh EL, Lingsma HF, Maas AI, Valadka AB, Okonkwo DO, Manley GT, Manley GT (2014) Acute biomarkers of traumatic brain injury: relationship between plasma levels of ubiquitin C-terminal hydrolase-L1 and glial fibrillary acidic protein. J Neurotrauma 31:19-25. CrossRef Medline

Farace E, Alves WM (2000) Do women fare worse: a metaanalysis of gender differences in traumatic brain injury outcome. J Neurosurg 93:539-545. CrossRef Medline

Faul M, Xu L, Wald M, Coronado V (2010) Traumatic brain injury in the
United States: emergency department visits, hospitalizations and deaths 2002-2006. Atlanta: Centers for Disease Control and Prevention, National Center for Injury Prevention and Control.

Haj-Yasein NN, Vindedal GF, Eilert-Olsen M, Gundersen GA, Skare Ø, Laake P, Klungland A, Thorén AE, Burkhardt JM, Ottersen OP, Nagelhus EA (2011) Glial-conditional deletion of aquaporin-4 (Aqp4) reduces bloodbrain water uptake and confers barrier function on perivascular astrocyte endfeet. Proc Natl Acad Sci U S A 108:17815-17820. CrossRef Medline

Herrmann M (2001) High serum S100B levels for trauma patients without head injuries. Neurosurgery 49:1272-1273. CrossRef Medline

Hoge CW, Goldberg HM, Castro CA (2009) Care of war veterans with mild traumatic brain injury-flawed perspectives. N Engl J Med 360:1588-1591. CrossRef Medline

Iliff JJ, Wang M, Liao Y, Plogg BA, Peng W, Gundersen GA, Benveniste H, Vates GE, Deane R, Goldman SA, Nagelhus EA, Nedergaard M (2012) A paravascular pathway facilitates CSF flow through the brain parenchyma and the clearance of interstitial solutes, including amyloid beta. Sci Trans Med 4:147ra111. CrossRef Medline

Iliff JJ, Lee H, Yu M, Feng T, Logan J, Nedergaard M, Benveniste H (2013a) Brain-wide pathway for waste clearance captured by contrast-enhanced MRI. J Clin Invest 123:1299-1309. CrossRef Medline

Iliff JJ, Wang M, Zeppenfeld DM, Venkataraman A, Plog BA, Liao Y, Deane R, Nedergaard M (2013b) Cerebral arterial pulsation drives paravascular CSF-interstitial fluid exchange in the murine brain. J Neurosci 33:1819018199. CrossRef Medline

Iliff JJ, Chen MJ, Plog BA, Zeppenfeld DM, Soltero M, Yang L, Singh I, Deane R, Nedergaard M (2014) Impairment of glymphatic pathway function promotes tau pathology after traumatic brain injury. J Neurosci 34: 16180-16193. CrossRef Medline.

Jeter CB, Hergenroeder GW, Hylin MJ, Redell JB, Moore AN, Dash PK (2013) Biomarkers for the diagnosis and prognosis of mild traumatic brain injury/concussion. J Neurotrauma 30:657-670. CrossRef Medline

Johnston M, Papaiconomou C (2002) Cerebrospinal fluid transport: a lymphatic perspective. Physiology 17:227-230. CrossRef Medline

Johnston M, Zakharov A, Papaiconomou C, Salmasi G, Armstrong D (2004) Evidence of connections between cerebrospinal fluid and nasal lymphatic vessels in humans, non-human primates and other mammalian species. Cerebrospinal Fluid Res 1:2. CrossRef Medline

Kaipainen A, Korhonen J, Mustonen T, van Hinsbergh VW, Fang GH, Dumont D, Breitman M, Alitalo K (1995) Expression of the fms-like tyrosine kinase 4 gene becomes restricted to lymphatic endothelium during development. Proc Natl Acad Sci U S A 92:3566-3570. CrossRef Medline

Katada R, Akdemir G, Asavapanumas N, Ratelade J, Zhang H, Verkman AS (2014) Greatly improved survival and neuroprotection in aquaporin-4knockout mice following global cerebral ischemia. FASEB J 28:705-714. CrossRef Medline

Kövesdi E, Lückl J, Bukovics P, Farkas O, Pál J, Czeiter E, Szellár D, Dóczi T, Komoly S, Büki A (2010) Update on protein biomarkers in traumatic brain injury with emphasis on clinical use in adults and pediatrics. Acta Neurochir 152:1-17. CrossRef Medline

Kurland D, Hong C, Aarabi B, Gerzanich V, Simard JM (2012) Hemorrhagic progression of a contusion after traumatic brain injury: a review. J Neurotrauma 29:19-31. CrossRef Medline

Langlois JA, Sattin RW (2005) Traumatic brain injury in the United States: research and programs of the Centers for Disease Control and Prevention (CDC). J Head Trauma Rehabil 20:187-188. CrossRef Medline

Liang D, Bhatta S, Gerzanich V, Simard JM (2007) Cytotoxic edema: mechanisms of pathological cell swelling. Neurosurg Focus 22:1-9. CrossRef Medline

Manaenko A, Chen H, Kammer J, Zhang JH, Tang J (2011) Comparison Evans Blue injection routes: intravenous versus intraperitoneal, for measurement of blood-brain barrier in a mice hemorrhage model. J Neurosci Methods 195:206-210. CrossRef Medline

Manley GT, Fujimura M, Ma T, Noshita N, Filiz F, Bollen AW, Chan P, Verkman AS (2000) Aquaporin-4 deletion in mice reduces brain edema after acute water intoxication and ischemic stroke. Nat Med 6:159-163. CrossRef Medline

Mannix R, Meehan WP, Mandeville J, Grant PE, Gray T, Berglass J, Zhang J, Bryant J, Rezaie S, Chung JY, Peters NV, Lee C, Tien LW, Kaplan DL, Feany M, Whalen M (2013) Clinical correlates in an experimental model of repetitive mild brain injury. Ann Neurol 74:65-75. CrossRef Medline 
Marmarou A (2004) The pathophysiology of brain edema and elevated intracranial pressure. Cleve Clinic J Med 71 [Suppl 1]:S6-S8. CrossRef Medline

Marmarou A (2007) A review of progress in understanding the pathophysiology and treatment of brain edema. Neurosurg Focus 22:1-10. CrossRef Medline

Mondello S, Muller U, Jeromin A, Streeter J, Hayes RL, Wang KK (2011) Blood-based diagnostics of traumatic brain injuries. Expert Rev Mol Diagn 11:65-78. CrossRef Medline

Murtha LA, Yang Q, Parsons MW, Levi CR, Beard DJ, Spratt NJ, McLeod DD (2014) Cerebrospinal fluid is drained primarily by the spinal canal and olfactory route in young and aged spontaneously hypertensive rats. Fluids Barriers CNS 11:12. CrossRef Medline

Obermeier B, Daneman R, Ransohoff RM (2013) Development, maintenance and disruption of the blood-brain barrier. Nat Med 19:1584-1596. CrossRef Medline

Olsson B, Zetterberg H, Hampel H, Blennow K (2011) Biomarker-based dissection of neurodegenerative diseases. Prog Neurobiol 95:520-534. CrossRef Medline

Papa L, Ramia MM, Kelly JM, Burks SS, Pawlowicz A, Berger RP (2013) Systematic review of clinical research on biomarkers for pediatric traumatic brain injury. J Neurotrauma 30:324-338. CrossRef Medline

Papadopoulos MC, Verkman AS (2005) Aquaporin-4 gene disruption in mice reduces brain swelling and mortality in pneumococcal meningitis. J Biol Chem 280:13906-13912. CrossRef Medline

Papadopoulos MC, Verkman AS (2007) Aquaporin-4 and brain edema. Pediatr Nephrol 22:778-784. CrossRef Medline

Papadopoulos MC, Manley GT, Krishna S, Verkman AS (2004) Aquaporin-4 facilitates reabsorption of excess fluid in vasogenic brain edema. FASEB J 18:1291-1293. CrossRef Medline

Rangroo Thrane V, Thrane AS, Plog BA, Thiyagarajan M, Iliff JJ, Deane R, Nagelhus EA, Nedergaard M (2013) Paravascular microcirculation facilitates rapid lipid transport and astrocyte signaling in the brain. Sci Rep 3:2582. CrossRef Medline

Ren Z, Iliff JJ, Yang L, Yang J, Chen X, Chen MJ, Giese RN, Wang B, Shi X, Nedergaard M (2013) 'Hit and Run' model of closed-skull traumatic brain injury (TBI) reveals complex patterns of post-traumatic AQP4 dysregulation. J Cereb Blood Flow Metab 33:834-845. CrossRef Medline

Roozenbeek B, Maas AI, Menon DK (2013) Changing patterns in the epidemiology of traumatic brain injury. Nat Rev Neurol 9:231-236. CrossRef Medline

Simard JM, Kent TA, Chen M, Tarasov KV, Gerzanich V (2007) Brain oedema in focal ischaemia: molecular pathophysiology and theoretical implications. Lancet Neurol 6:258-268. CrossRef Medline

Simard JM, Kahle KT, Gerzanich V (2010) Molecular mechanisms of microvascular failure in central nervous system injury: synergistic roles of NKCC1 and SUR1/TRPM4. J Neurosurg 113:622-629. CrossRef Medline Simard JM, Woo SK, Schwartzbauer GT, Gerzanich V (2012) Sulfonylurea receptor 1 in central nervous system injury: a focused review. J Cereb Blood Flow Metab 32:1699-1717. CrossRef Medline

Simard M, Nedergaard M (2004) The neurobiology of glia in the context of water and ion homeostasis. Neuroscience 129:877-896. CrossRef Medline

Statler KD, Alexander H, Vagni V, Holubkov R, Dixon CE, Clark RS, Jenkins L, Kochanek PM (2006) Isoflurane exerts neuroprotective actions at or near the time of severe traumatic brain injury. Brain Res 1076:216-224. CrossRef Medline

Stone JJ, Childs S, Smith LE, Battin M, Papadakos PJ, Huang JH (2014) Hourly neurologic assessments for traumatic brain injury in the ICU. Neurol Res 36:164-169. CrossRef Medline

Tagliaferri F, Compagnone C, Korsic M, Servadei F, Kraus J (2006) A systematic review of brain injury epidemiology in Europe. Acta Neurochir 148:255-268. CrossRef Medline

Takeda S, Sato N, Ikimura K, Nishino H, Rakugi H, Morishita R (2011) Novel microdialysis method to assess neuropeptides and large molecules in free-moving mouse. Neuroscience 186:110-119. CrossRef Medline

Thorne RG, Nicholson C (2006) In vivo diffusion analysis with quantum dots and dextrans predicts the width of brain extracellular space. Proc Natl Acad Sci U S A 103:5567-5572. CrossRef Medline

Thrane AS, Rappold PM, Fujita T, Torres A, Bekar LK, Takano T, Peng W, Wang F, Rangroo Thrane V, Enger R, Haj-Yasein NN, Skare Ø, Holen T, Klungland A, Ottersen OP, Nedergaard M, Nagelhus EA (2011) Critical role of aquaporin-4 (AQP4) in astrocytic $\mathrm{Ca}^{2+}$ signaling events elicited by cerebral edema. Proc Natl Acad Sci U S A 108:846-851. CrossRef Medline

Ulrich JD, Burchett JM, Restivo JL, Schuler DR, Verghese PB, Mahan TE, Landreth GE, Castellano JM, Jiang H, Cirrito JR, Holtzman DM (2013) In vivo measurement of apolipoprotein $\mathrm{E}$ from the brain interstitial fluid using microdialysis. Mol Neurodegener 8:13. CrossRef Medline

Vogh BP, Godman DR, Maren TH (1987) Effect of AlCl3 and other acids on cerebrospinal fluid production: a correction. J Pharmacol Exp Ther 243: 35-39. Medline

Xie L, Kang H, Xu Q, Chen MJ, Liao Y, Thiyagarajan M, O’Donnell J, Christensen DJ, Nicholson C, Iliff JJ, Takano T, Deane R, Nedergaard M (2013) Sleep drives metabolite clearance from the adult brain. Science 342:373-377. CrossRef Medline

Xiong Y, Mahmood A, Chopp M (2013) Animal models of traumatic brain injury. Nat Rev Neurosci 14:128-142. CrossRef Medline

Yamada K, Cirrito JR, Stewart FR, Jiang H, Finn MB, Holmes BB, Binder LI, Mandelkow EM, Diamond MI, Lee VM, Holtzman DM (2011) In vivo microdialysis reveals age-dependent decrease of brain interstitial fluid tau levels in P301S human tau transgenic mice. J Neurosci 31:13110-13117. CrossRef Medline

Zetterberg H, Smith DH, Blennow K (2013) Biomarkers of mild traumatic brain injury in cerebrospinal fluid and blood. Nat Rev Neurol 9:201-210. CrossRef Medline 